\title{
Sigle wall carbon nanotubes decorated with selenium nanoparticles
}

\author{
Oscar E. D. Rodrigues, ${ }^{a}$ A. G. Souza Filho, ${ }^{b}$ Josué M. Filho, ${ }^{b}$ Luciano Dornelles $^{\mathrm{a}(\mathrm{PQ})}$, \\ Letiére C. Soares, ${ }^{a^{\star}}$ Diego de Souza ${ }^{a}$ \\ a Universidade Federal de Santa Maria, Chemistry Departament, Santa Maria-RS, 97105-900, Brazil. \\ ${ }^{b}$ Universidade Federal do Ceará - Depto. de Física, Campus do PICI \\ *e-mail: rodriguesoed@smail.ufsm.br
}

Keywords: Selenium, Nanowires, carbon-nanotube

\section{INTRODUCTION}

The chemical manipulation of single walled carbon nanotubes (SWNTs), especially the side walls funtionalization, has been an area of fundamental interest. Single walled carbon nanotube has opened a Pandora's box for new electronic devices nanoestructured. ${ }^{1}$

Additionally, selenium exhibits a unique combination of many properties ${ }^{2}$ as a relatively low meting point $\left(\sim 217^{\circ} \mathrm{C}\right)$, piezoelectricity, non-linear optical response and high reaction flexibility with a number of chemical compounds that enable the achievement of a broad class of compounds of selenium, as $\mathrm{ZnSe}$ and CdSe. In this context, the preparation of a new hybrid system employing one-dimensional selenium nanostructures (Se-1D) and carbon nanotubes can afford a very interesting system for technological applications. In a previous publication, ${ }^{3}$ we have prepared a new selenium-carbon nanocable, employing a carbanionic intermediate species. This allowed an effective linkage between selenium and carbon nanotube sidewall, affording a covalent bond between this components.

\section{RESULTS AND DISCUSSION}

To explore the potential of this reaction and the possibilities to interact selenium and carbon nanotubes, we describe here a new synthesis of SWNT decorated with selenium nanoparticles, using a weaker core-shell Van der Walls interaction, as showing in the figure 1. The nanohybrid material is composed of selenium nanowires and HipCo carbon nanotubes as a physical support. The resulting material was characterized using Raman spectroscopy and transmission electron microscopy (TEM). The results showed the new hybrid system as a carbon nanotubes coated with a layer of helical selenium nanowires interacting via a Van der Waals, as show in figure 1.
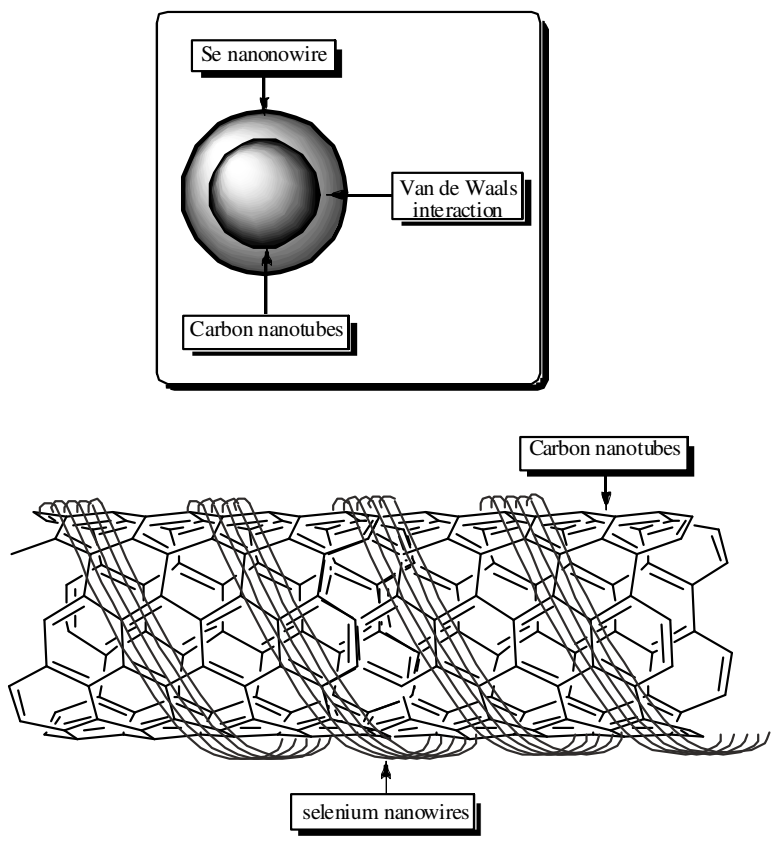

Figure 1. SWNT decorated with selenium nanoparticles

\section{CONCLUSION}

In this work, we developed a new methodology for the preparation of single wall carbon nanotubes decorated with selenium nanoparticles. The preparation of new hybrid systems involving sulfur and tellurium are being completed in our research group.

\section{ACKNOWLEDGEMENTS}

CAPES, CNPq, FAPERGS.

\section{REFERENCES}

${ }^{1}$ Chiu, P. W.; Duesberg, G. S.; Dettlaff-Weglikowska, U.; Roth, S. Appl. Phys. Lett., 2002, 80, 3811.

${ }^{2}$ Berger, L. I.; Semiconductor Materials, 1997, 86

${ }^{3}$ Rodrigues, O. E D.; Saraiva, G. D.; Nascimento, R. O.; Barros, E. B.; Mendes Filho, J.; Kim, Y. A.; Muramatsu, H.; Endo, M.; Terrones, M.; Dresselhaus, M. S.; Souza Filho A. G. Nano Lett., 2008, 11, 3651 